\title{
Design of substrate integrated waveguide with Minkowski-Sierpinski fractal antenna for WBAN applications
}

\author{
Mustafa Mohammed Jawad ${ }^{1}$, Nik Noordini Nik Abd Malik ${ }^{2}$, Noor Asniza Murad ${ }^{3}$, \\ Mohd Riduan Ahmad ${ }^{4}$, Mona Riza Mohd Esa ${ }^{5}$, Yaqdhan Mahmood Hussein ${ }^{6}$ \\ ${ }^{1,2,3,5,6}$ School of Electrical Engineering, Faculty of Engineering, Universiti Teknologi Malaysia, Johor Bahru, Malaysia \\ ${ }^{4}$ Universiti Teknikal Malaysia Melaka, Malaysia
}

\begin{tabular}{l} 
Article Info \\
\hline Article history: \\
Received Feb 10, 2020 \\
Revised Apr 23, 2020 \\
Accepted May 30, 2020 \\
\hline
\end{tabular}

Keywords:

CST

Fractal antenna

mm-Wave

SIW

WBAN

\begin{abstract}
This paper presents a new design of patch antenna using Minkowski-Sierpinski fractal technique with substrate integrated waveguide (SIW) to resonate at $60 \mathrm{GHz}$. The antenna is proposed to be used for wireless body area network applications (WBAN). The proposed antenna is implemented using Rogers 5880 substrate with permittivity of $\left(\varepsilon_{\mathrm{r}}\right)$ of 2.2 and loss tangent is 0.0004 , height of the substrate is $0.381 \mathrm{~mm}$. Computer simulation technology-Microwave Studio (CST-MW) is used to simulate the proposed antenna. The simulated results show a wide bandwidth of $3.5 \mathrm{GHz}$ between the ranges of (58.3-61.7) GHz, with a good return loss of more than $-10 \mathrm{~dB}$. A simulated gain of $7.9 \mathrm{~dB}$ is achieved with a linear antenna efficiency of $91 \%$. This proposed antenna is used to improve the quality of radiation pattern, bandwidth, and gain at millimetre wave (mm-Wave) band for WBAN applications.
\end{abstract}

This is an open access article under the CC BY-SA license.

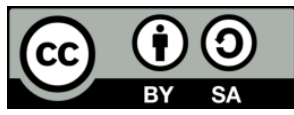

Corresponding Author:

Nik Noordini Nik Abd Malik,

School of Electrical Engineering, Faculty of Engineering,

Universiti Teknologi Malaysia,

81310 UTM Johor Bahru, Malaysia.

Email: noordini@utm.my

\section{INTRODUCTION}

Body-implanted electronics came into existence when the first pacemaker was invented in the 1950s [1]. This healthcare innovation exposed the potential and revealed vast opportunities in the field of implantable electronic devices, enabling new ways of diagnostics and treatment. Wireless implantable bioelectronics is a fast-growing field having many potential applications in medicine, clinical research, professional sports, occupational health, and defence while maintaining a patient's mobility [2-4]. The term "wireless body area network (WBAN)" refers to the networking process that is related to human himself/herself and or human to another human network oneself and to other persons networking [5]. Then rise in interest can be seen in this technology from academics and industries [6-9]. During the last twenty years [10-12], an amount of investigation has been observed in the area of WBANs.

Most of researchers use high frequency rather than low frequency in order to overcome the disadvantages of low frequency such as interfacing and low penetration depth $[13,14]$. Signals are supposed to be intermixed due to long-distance and interfere among other frequencies. This happens in order to control radiation. The need is to increase the size of antennas with the objective of achieving large wavelength [15, 16]. The situation reverses when the frequency of bands is higher. Selection of frequency seems like a compromise between propagation loss, the interference strength, antenna and the rates for data. In recent studies, these two bands of ISM and UWB have widely implemented in the WBAN band applications [17, 18].

The recent research suggested that WBAN networks at $60 \mathrm{GHz}$ will perform much better than those at low frequencies, in terms of coexistence with neighbouring WBAN networks, and immunity from 
interference and interference in other systems [19, 20]. These benefits are expected to be obtained through more advanced BAN and higher-gain antennas, some of which are reproducible. First fractal geometry was proposed by Mandelbrot et al. [21, 22]. Since that time, widespread applications have been found in fractal shapes. This topic has been discussed by several branches of science and engineering that have included antenna design in their discussion [23, 24]. Fractal forms have already been shown to be very efficient in the design of compact antennas with a low profile. More than that, the increase in multiband operation, bandwidth and enhance gain are the other characteristics. There are different shapes of fractal geometries have been calculated such as Sierpinski gasket and Minkowski carpet [25].

In this work, Minkowski-Sierpinski fractal technique with SIW resonate at $60 \mathrm{GHz}$ for WBANs is proposed. The results obtained of the proposed design are $7.9 \mathrm{~dB}$ gain, $8.51 \mathrm{dBi}$ directivity and $-18.65 \mathrm{~dB}$ return loss. The results have compared with other designs and have shown improvement of $70 \%$ gain, $12 \%$ efficiency, and $20 \%$ reduced the size.

\section{RESEARCH METHOD}

The general structure of SIW is shown in Figure 1. It consists of a rectangular waveguide, two rows of periodic holes, and a substrate at the top and bottom of ground planes [26, 27]. As can be seen from Figure 1, the parameters of the SIW should be taken in consideration. The width between the vias can be found by [28]:

$$
a_{R}=w-\frac{D^{2}}{0.85 S^{2}}
$$

where $a_{R}$ is the waveguide width, $D$ is the diameter of the vias, and $S$ is the spacing between each vias. The diameter of the vias and the spacing can be calculated using [28]:

$$
\begin{aligned}
& D \leq \frac{\lambda_{g}}{5} \\
& S \leq 2 D \\
& a_{R}=\frac{a}{\sqrt{\varepsilon_{r}}}
\end{aligned}
$$

where $a$ is the width of the rectangular waveguide standard, and $\lambda_{g}$ is the guided wavelength of the SIW [28]:

$$
\lambda_{g}=\frac{2 \pi}{\sqrt{\frac{\varepsilon_{r}(2 \pi f)^{2}}{c^{2}}-\left(\frac{\pi}{a}\right)^{2}}}
$$

where $f$ is the desired frequency, $c$ is the speed of light, and $\varepsilon_{r}$ is the substrate permittivity.

The proposed antenna is designed using Roger 5880 substrate. Figure 2 shows the geometrical structures of the SIW Minkowski-Sierpinski carpet fractal antenna at $60 \mathrm{GHz}$. The substrate using Roger 5880 substrate with $\varepsilon_{\mathrm{r}}=2.2$ and thickness of substrate is $0.381 \mathrm{~mm}$, while the patch and ground are using copper with thickness $\mathrm{h}=0.035 \mathrm{~mm}$. By using (1) to (5), the diameter, spacing of holes, and the width between holes can be determined at desired frequency of $60 \mathrm{GHz}$. Table 1 summarizes the final dimension of the proposed antenna.

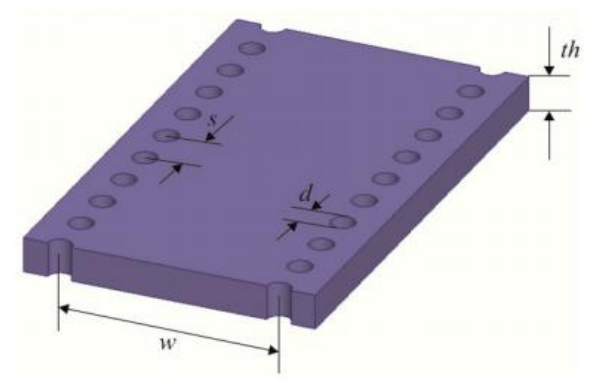

Figure. 1. The prospective general structure of a substrate integrated waveguide [28] 


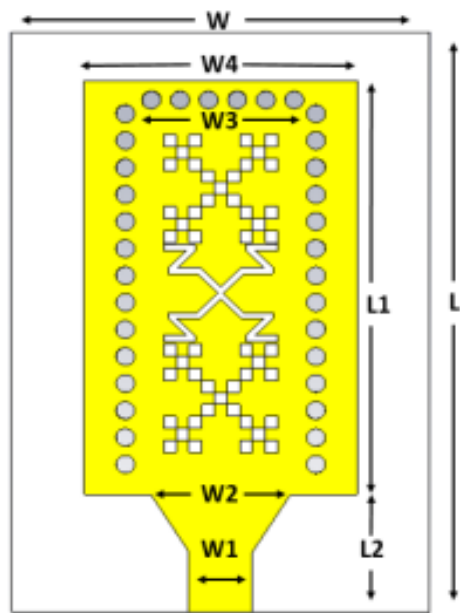

(a)

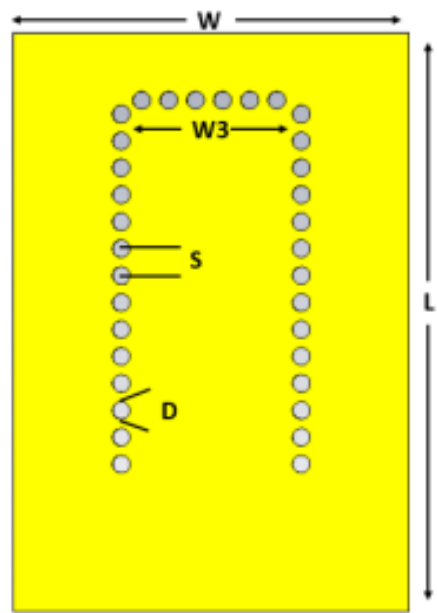

(b)

Figure 2. The proposed structure of SIW with Minkowski-Sierpinski fractal antenna, (a) Top view, (b) Bottom view

Table 1. The final parameters values of the proposed antenna with SIW (all dimensions in mm)

\begin{tabular}{llll}
\hline Variable & Patch & Substrate & Ground \\
\hline$W$ & - & 6.5 & 6.5 \\
$L$ & - & 9.6 & 9.6 \\
$W 3$ & 3 & 3 & 3 \\
$L 1$ & 6.9 & - & - \\
L2 & 0.98 & - & - \\
$W 2$ & 2.2 & - & - \\
$W 1$ & 1 & - & - \\
$S$ & 0.45 & 0.45 & 0.45 \\
$D$ & 0.3 & 0.3 & 0.3 \\
$h$ & 0.035 & 0.381 & 0.035 \\
Material & Copper & Rogers 5880 & Copper \\
\hline
\end{tabular}

\section{RESULTS AND DISCUSSION}

The proposed antenna is simulated by CST microwave software. The simulated reflection coefficient $\left(\mathrm{S}_{11}\right)$ is plotted in Figure 3. It can be clearly noticed that the reflection value is less than $-10 \mathrm{~dB}$ at desired frequency, with an excellent bandwidth of $3.5 \mathrm{GHz}(58.3$ to $61.7 \mathrm{GHz})$. With maximum value of $-10 \mathrm{~dB}$ at 58.3 and $61.7 \mathrm{GHz}$, and minimum value of $-18.56 \mathrm{~dB}$ at $60 \mathrm{GHz}$.

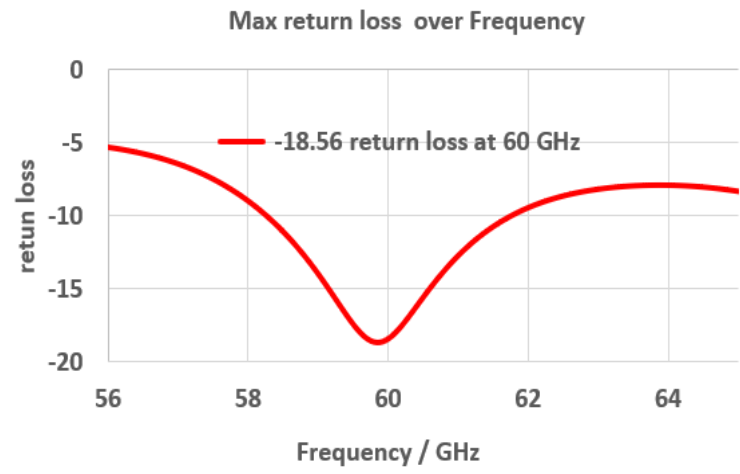

Figure 3. Simulated return loss $\left(\mathrm{S}_{11}\right)$ of the proposed antenna

The gain of the simulated antenna is shown in Figure 4, over the operated bandwidth of $3.5 \mathrm{GHz}$. The maximum gain of $7.92 \mathrm{~dB}$ is obtained at $60 \mathrm{GHz}$. The gain values are varying between 7 to $7.98 \mathrm{~dB}$ over the frequency range of 58.3-61.7 GHz). In another hand, the simulated antenna achieved a directivity of 
$8.5 \mathrm{dBi}$ at $60 \mathrm{GHz}$ as shown in Figure 5. The efficiency of the propose antenna can be found in Figure 6 . The antenna achieved a high linear efficiency of $91 \%$ at $60 \mathrm{GHz}$. However, the average efficiency along the bandwidth is $(3.5 \mathrm{GHz})$.

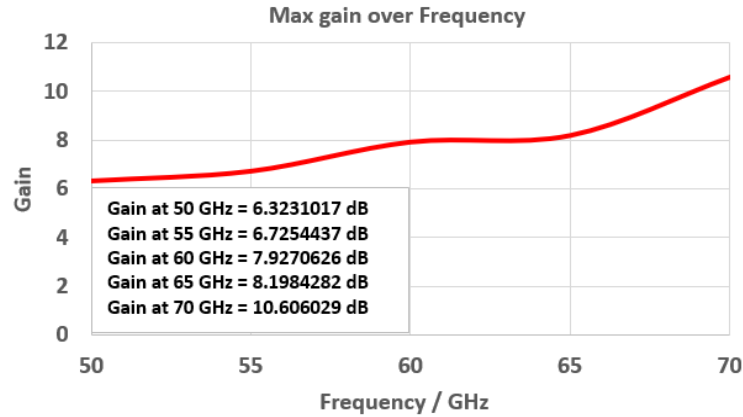

Figure 4. The simulated gain of the proposed antenna

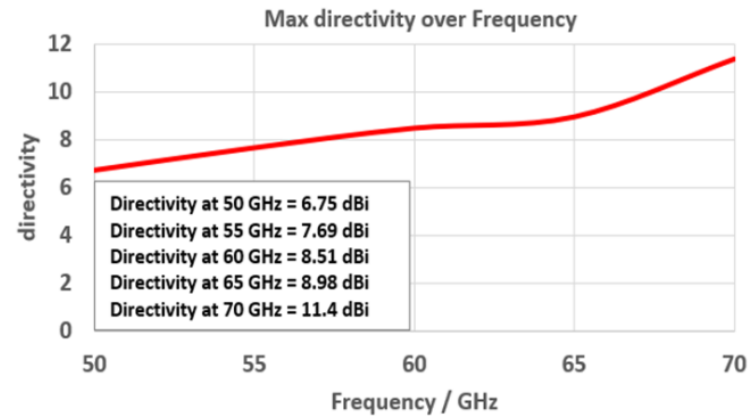

Figure 5. The simulated directivity of the proposed antenna

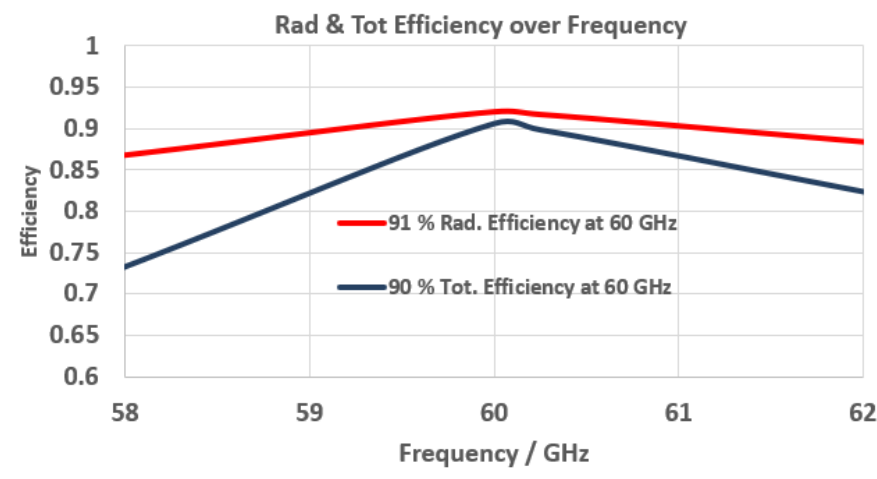

Figure 6. The efficiency of the proposed antenna

The radiation pattern of the proposed antenna at $60 \mathrm{GHz}$ is illustrated in Figure 7. The radiation has a beam width of $25^{\circ}$ in the main lobe direction, with side lobes of -5 to $-10 \mathrm{dBi}$. Despite this unwanted side lobes, the main lobe directivity is about $8.51 \mathrm{dBi}$. Additionally, Figure 8 illustrates the surface current of the suggested $60 \mathrm{GHz}$ antenna. Table 2 summarizes the simulated results of the SIW Minkowski-Sierpinski fractal antenna. Table 3 shows the comparison between the proposed designs with other work.
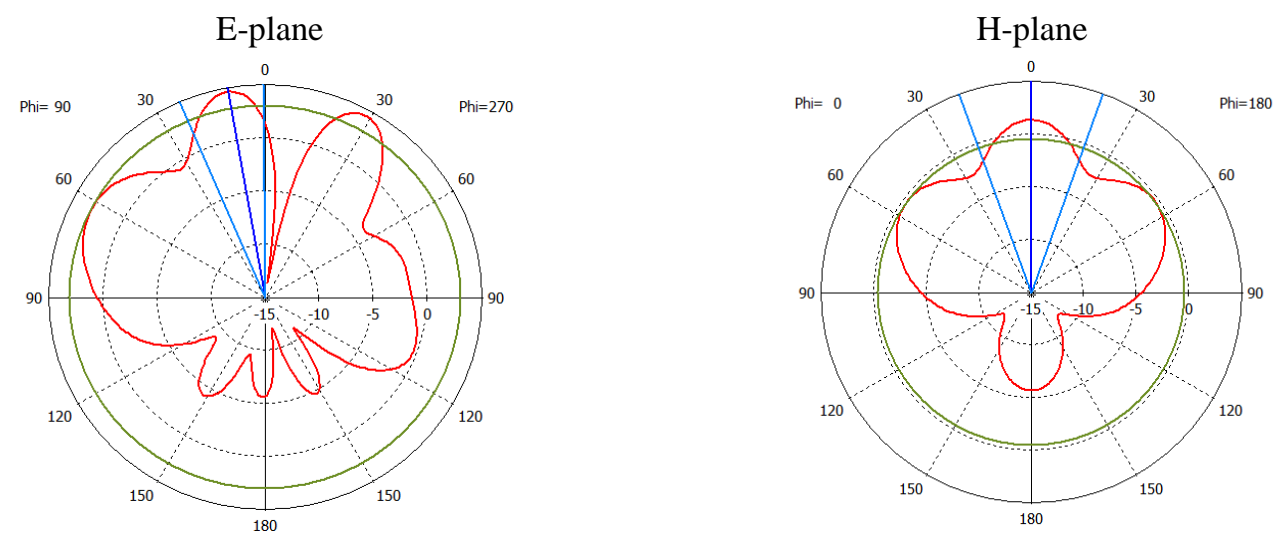

Figure 7. The radiation pattern of the proposed SIW antenna at $60 \mathrm{GHz}$ 

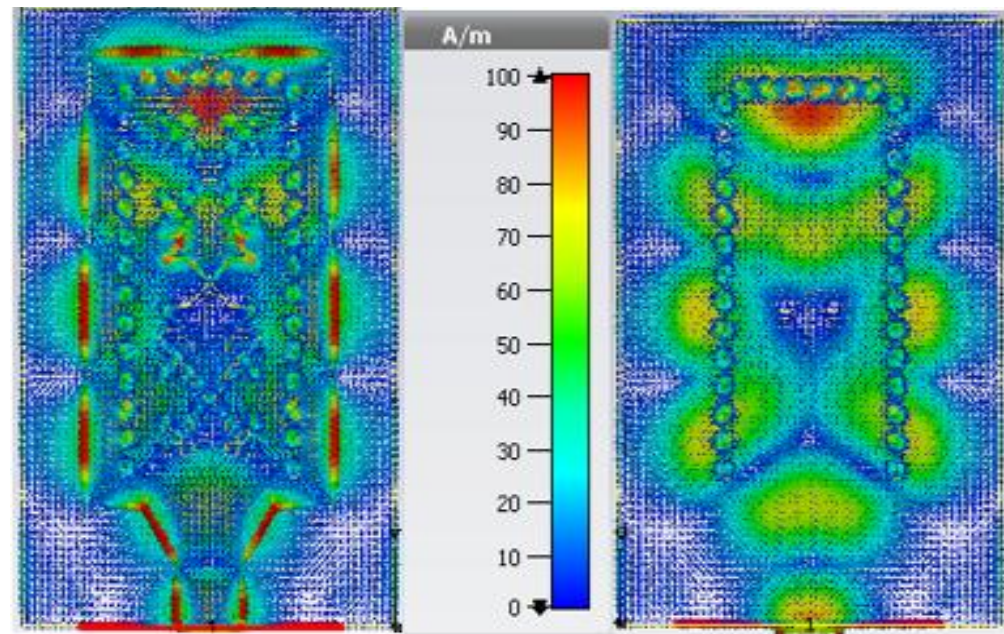

Figure 8. The surface current at $60 \mathrm{GHz}$

Table 2. The simulated results of the proposed antenna at $60 \mathrm{GHz}$

\begin{tabular}{ll}
\hline Parameter value & Parameter value \\
\hline Gain & $7.9 \mathrm{~dB}$ \\
VSWR & 1.27 \\
Reflection coefficient & $-18.56 \mathrm{~dB}$ \\
Radiation efficiency & $91 \%$ \\
Transmission Efficiency & $90 \%$ \\
Directivity & $8.51 \mathrm{dBi}$ \\
\hline
\end{tabular}

Table 3. Comparative results of different SIW-born antennas

\begin{tabular}{llllll}
\hline Ref. & Operating freq. (GHz) & Substrate/dielectric constant & Gain $(\mathrm{dB})$ & B.W $(\mathrm{GHz})$ & Effi. (\%) \\
\hline$[29]$ & 60 & Rogers 5800 & 4.57 & 4 & 85 \\
{$[30]$} & $60-79$ & Rogers 5800 & $6-6.78$ & $2.25-3.05$ & 86 \\
{$[31]$} & 60 & Rogers 5800 & 4.45 & 5 & 81 \\
This work & 60 & Rogers 5800 & 7.9 & 3.5 & 91 \\
\hline
\end{tabular}

\section{CONCLUSION}

This paper presented the design of SIW Minkowski-Sierpinski ground fractal antenna at $60 \mathrm{GHz}$. A wide bandwidth of $3.5 \mathrm{GHz}$ is obtained. A good return loss of more than $-10 \mathrm{~dB}$ is achieved at $60 \mathrm{GHz}$. The antenna has a good directivity of $8.5 \mathrm{dBi}$ and a gain of $7.9 \mathrm{~dB}$. Also, the antenna has excellent linear efficiency between $90-91 \%$ over the required bandwidth. The proposed design of this antenna is suitable for WBANs applications. For Future work, the proposed antenna can be designed in the form of array to enhance the efficiency, gain and directivity

\section{ACKNOWLEDGEMENTS}

The authors would like to thank all who contributed toward making this research successful. The authors wish to express their gratitude to Ministry of Higher Education (MOHE), Research Management Center (RMC) for the sponsorship, Universiti Teknologi Malaysia for the financial support and advice for this project. (Vot number: PY/2019/01958 and PY/2018/03419).

\section{REFERENCES}

[1] D. Nikolayev, M. Zhadobov, P. Karban, and R. Sauleau, "Conformal antennas for miniature in-body devices: The quest to improve radiation performance," URSI Radio Science Bulletin, vol. 2017, no. 363, pp. 52-64, 2017.

[2] H. C. Koydemir and A. Ozcan, "Wearable and implantable sensors for biomedical applications," Annual Review of Analytical Chemistry, vol. 11, no, 1, pp. 127-146, 2018.

[3] R. Punj and R. Kumar, "Technological aspects of WBANs for health monitoring: a comprehensive review," Wireless Networks, vol. 25, pp. 1125-1157, 2019.

[4] D. Nikolayev, M. Zhadobov, R. Sauleau, and P. Karban, "Antennas for ingestible capsule telemetry," Advances in Body-Centric Wireless Communication: Applications and State-of-the-Art, IET, UK, pp. 143-186, 2016.

Design of substrate integrated waveguide with Minkowski-Sierpinski... (Mustafa Mohammed Jawad) 
[5] R. P. Feynman, "There's plenty of room at the bottom,” Engineering and Science Magazine, vol. 23, no. 5, 1960.

[6] B. Mohamadzade, R. M. Hashmi, Roy B. V. B. Simorangkir, R. Gharaei, S. Ur Rehman, and Q. H. Abbasi, "Recent advances in fabrication methods for flexible antennas in wearable devices: state of the art," Sensors, vol. 19, no. 10, pp. 2312-1-21, 2019.

[7] V. Oleshchuk, and R. Fensli, "Remote patient monitoring within a future 5G infrastructure," Wireless Personal Communications, vol. 57, no. 3. pp. 431-439, 2011.

[8] A. K. Teshome, B. Kibret, and D. T. H. Lai, "A review of implant communication technology in WBAN: Progress and challenges," IEEE Reviews in Biomedical Engineering, vol. 12, pp. 88-99, 2019.

[9] S. Movassaghi, M. Abolhasan, J. Lipman, D. Smith, and A. Jamalipour, "Wireless body area networks: A survey," IEEE Communications Surveys \& Tutorials, vol. 16, no. 3, pp. 1658-1686, 2014.

[10] N. Chahat, M. Zhadobov, R. Sauleau, and K. Ito, "A compact UWB antenna for on-body applications," IEEE Transactions on Antennas and Propagation, vol. 59, no. 4, pp. 1123-1131, April 2011.

[11] H. Wong, K. Luk, C. H. Chan, Q. Xue, K. K. So, and H. W. Lai, "Small antennas in wireless communications," Proceedings of the IEEE, vol. 100, no. 7, pp. 2109-2121, July 2012.

[12] A. Karimbu Vallappil, B. A. Khawaja, I. Khan, and M. Mustaqim, "Dual-band Minkowski-Sierpinski fractal antenna for next generation satellite communications and wireless body area networks," Microwave and Optical Technology Letters, vol. 60, pp. 171-178, 2018.

[13] C. G. Christodoulou, Y. Tawk, S. A. Lane, and S. R. Erwin, "Reconfigurable antennas for wireless and space applications," Proceedings of the IEEE, vol. 100, no. 7, pp. 2250-2261, July 2012.

[14] L. Akhoondzadeh-Asl, P. S. Hall, Y. Nechayev, and I. Khan, "Depolarization in on-body communication channels at $2.45 \mathrm{GHz}$," IEEE Transactions on Antennas and Propagation, vol. 61, no. 2, pp. 882-889, Feb. 2013.

[15] Y. I. Nechayev, Z. H. Hu, and P. S. Hall, "Short-term and long-term fading of on-body transmission channels at $2.45 \mathrm{GHz}, " 2009$ Loughborough Antennas \& Propagation Conference, pp. 657-660, 2009.

[16] Y. I. Nechayev, P. S. Hall, and Z. H. Hu, "Characterisation of narrowband communication channels on the human body at 2.45 GHz," IET Microwaves, Antennas \& Propagation, vol. 4, no. 6, pp. 722-732, June 2010.

[17] A. R. O. Mumi, R. Alias, J. Abdullah, S. H. Dahlan, and J. Ali., "Assessment of electromagnetic absorption towards human head using specific absorption rate," Bulletin of Electrical Engineering and Informatics, vol. 7, no. 4, pp. 657-664, 2018.

[18] N. B. Asan, E. Hassan, J. V. S. R. Mohd Shah, D. Noreland, T. J. Blokhuis, E. Wadbro, M.Berggren, T. Voigt, and R. Augustine, "Characterization of the fat channel for intra-body communication at R-band frequencies," Sensors, vol. 18, no. 9, pp. 2752-1-16, 2018.

[19] Y. Hong, J. Tak, Y. Jin, and J. Choi, "A compact planar multi-band antenna with coupling feed for LTE/GSM/UMTS operations," 2014 International Symposium on Antennas and Propagation Conference Proceedings, pp. 501-502, 2014.

[20] Y. Hong and J. Choi, "60 GHz patch antenna array with parasitic elements for smart glasses," IEEE Antennas and Wireless Propagation Letters, vol. 17, no. 7, pp. 1252-1256, July 2018.

[21] H. Kumar, R. Jadhav, and S. Ranade, "A review on substrate integrated waveguide and its microstrip interconnect," Journal of Electronics and Communication Engineering, vol. 3, no. 5, pp. 36-40, 2012.

[22] A. Zabri, M. K. A. Rahim, F. Zubir, N. M. Nadzir, and H. A. Majid, "Fractal Yagi-Uda antenna for WLAN applications," TELKOMNIKA Telecommunication, Computing, Electronics and Control, vol. 17, no. 5, pp. 2155-2160, 2019.

[23] I. S. Bangi and J. S. Sivia, "Minkowski and Hilbert curves based hybrid fractal antenna for wireless applications," AEU-International Journal of Electronics and Communications, vol. 85, pp. 159-168, 2018.

[24] Y. Li, L. Li, Y. Zhang, and C. Zhao, "Design and synthesis of multilayer frequency selective surface based on antenna-filter-antenna using Minkowski fractal structures," IEEE Transactions on Antennas and Propagation, vol. 63, no. 1, pp. 133-141, Jan. 2015.

[25] J. A. Fan, W-H. Yeo, Y. Su, Y. Hattori, W. Lee, S-Y. Jung, Y. Zhang, Z. Liu, H. Cheng, L. Falgout, M. Bajema, T. Coleman, D. Gregoire, R. J. Larsen, Y. Huang, and J. A. Rogers "Fractal design concepts for stretchable electronics," Nature Communications, vol. 5 no. 1, pp. 1-8, 2014.

[26] M. Bozzi, A. Georgiadis, and K. Wu, "Review of substrate-integrated waveguide circuits and antennas," IET Microwaves, Antennas \& Propagation, vol. 5, no. 8, pp. 909-920, June 2011.

[27] Arvind Kumar and S. Raghavan, "A review: substrate integrated waveguide antennas and arrays," Journal of Telecommunication, Electronic and Computer Engineering (JTEC), vol. 8, no. 5, pp. 95-104, 2016.

[28] G. Venanzoni, D. Mencarelli, A. Morini, M. Farina, and F. Prudenzano, "Review of substrate integrated waveguide circuits for beam-forming networks working in X-band," Applied Sciences, vol. 9, no. 5, pp. 1003-1-19, 2019.

[29] M. Nandakumar and T. Shanmuganantham, "SIW flower shaped fractal antenna backed with cavity for $60 \mathrm{GHz}$ frequency applications," 2018 International Conference on Computer, Communication, and Signal Processing (ICCCSP), pp. 1-4, 2018.

[30] M. N. Kumar and T. Shanmuganantham, "SIW-based slot antenna fed by microstrip for 60/79 GHz applications," Microelectronics, Electromagnetics and Telecommunications, pp. 741-748, 2019.

[31] D. Nikolayev, W. Joseph, A. Skrivervik, M. Zhadobov, L. Martens, and R. Sauleau, "Dielectric-loaded conformal microstrip antennas for versatile in-body applications," IEEE Antennas and Wireless Propagation Letters, vol. 18, no. 12, pp. 2686-2690, Dec. 2019. 


\section{BIOGRAPHIES OF AUTHORS}

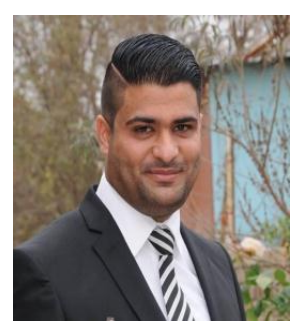

Mustafa Mohammed Jawad Abed was born in Baghdad, Iraq, He received the B.S in computer techniques engineering in 2010 from Al Rafidain University College in Baghdad city. and M.S. degrees in Electronic Engineering (Telecommunication System) from Universiti Teknikal Malaysia Melaka, Malaysia, in 2018, respectively, and he studies the Ph.D. degree in Electronic Engineering in Universiti Teknologi Malaysia in Johor Bahru city. His current research interests include wireless body area network, frequency-selective surface and substrate integrated waveguide antenna.
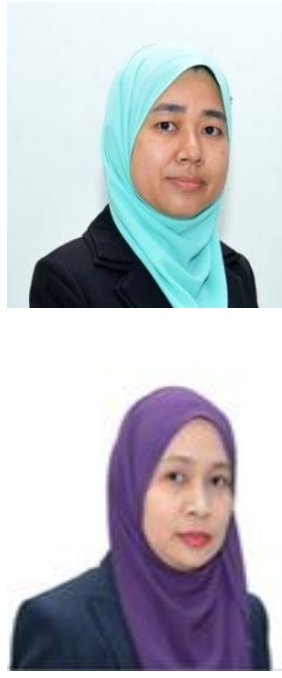

Nik Noordini Nik Abd Malik is a senior lecturer at the School of Electrical Engineering, Universiti Teknologi Malaysia (UTM), Malaysia. She received the Bachelor in Electrical Engineering (Telecommunication) from Universiti Teknologi Malaysia (UTM) in 2003. After that, she worked as a Radio Frequency R\&D Electrical Engineer in Motorola Technology Ptd. in Penang, Malaysia. She then received her master degree in Master of Engineering (MEng), Radio Frequency (RF) and Microwave Communication Engineering from University of Queensland, Australia (UQ) in 2005. She completed her Doctor of Philosophy (PhD) in Electrical Engineering at Universiti Teknologi Malaysia (UTM) in 2013. Her research interests include wireless sensor network, distributed beamforming, and meta-heuristic algorithms.

Noor Asniza Murad currently works at the School of Electrical Engineering, Faculty of Engineering, Universiti Teknologi Malaysia. Noor does research in antenna design as well as other microwave and millimeter wave devices. Her current research is on waveguide-based devices at millimeter wave.

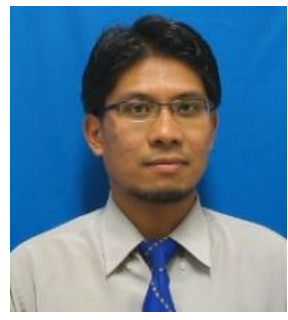

Mohd Riduan Ahmad was graduated from Universiti Putra Malaysia (UPM) with First Class Honors in Computer System and Communication Engineering in 2003. He obtained Master of Engineering from University of Wollongong, Australia in 2008 with specialization in crosslayer design of MAC protocols for MIMO-based wireless sensor network. In 2014, he awarded $\mathrm{PhD}$ degree with specialization in atmospheric discharges from Uppsala University, Sweden. He spent a year in MIT, USA from August 2015 to August 2016, worked on understanding and characterization of microwave radiation emitted by lightning flashes. Currently, he is a Senior Lecturer at Faculty of Electronics and Computer Engineering (FKEKK), Universiti Teknikal Malaysia Melaka (UTeM).

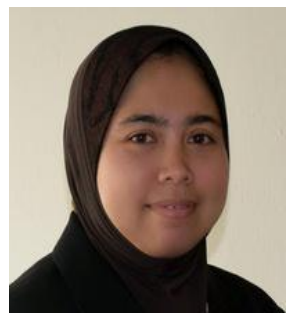

Mona Riza Mohd Esa was graduated from Universiti Teknologi Malaysia (UTM) with specialization in Telecommunication Engineering in 2003. She obtained master's degree from UTM in 2005 with specialization in signal processing and lightning physics. In 2014, she awarded $\mathrm{PhD}$ degree with specialization in atmospheric discharges from Uppsala University, Sweden. Currently, she is a Senior Lecturer and Deputy Director of Research, Networking and Commercialization in Institute of High Voltage and High Current, School of Electrical Engineering, Faculty of Engineering, Universiti Teknologi Malaysia (UTM) in Skudai, Johor.

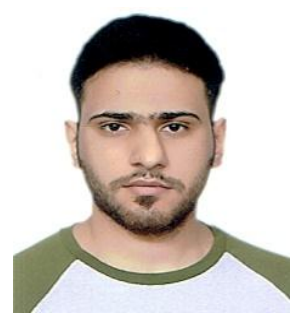

Yaqdhan Mahmood Hussein was born in Sammawah, Iraq, in 1991. He received the B.S in computer techniques engineering in 2014-2015 from Islamic University College in Najaf city. and M.S. degrees in electronic engineering (telecommunication system) from University technical Malaysia Melaka, Malaysia, in 2018, respectively, and he studies the Ph.D. degree in Electronic Engineering in Universiti Teknologi Malaysia in Johor Bahru city. His current research interests include millimeter wave antennas, base station antennas, and SIW technology with butler matrix. 